Thermodynamic properties of lithium chloride ammonia complexes under heat pump type II working conditions

Michel van der Pal

Jakobert Veldhuis 



\title{
THERMODYNAMIC PROPERTIES OF LITHIUM CHLORIDE AMMONIA COMPLEXES UNDER HEAT PUMP TYPE II WORKING CONDITIONS
}

\author{
Michel VAN DER PAL*, Jakobert VELDHUIS** \\ Unit Efficiency and Infrastructure, Energy research Centre of the Netherlands (ECN), \\ Westerduinweg 3, 1755 LE, Petten, The Netherlands. \\ *Author to whom correspondence should be addressed. \\ Tel: +31-224-564837, Fax: +31-224-568815, E-mail: vanderpal@ecn.nl \\ ** Author who will present this paper at IMPRES2010
}

\begin{abstract}
Heat pumps type II can be used for upgrading industrial waste heat to above pinch temperatures, with a typical lift from $130^{\circ} \mathrm{C}$ to $180^{\circ} \mathrm{C}$. At ECN such a heat pump is developed based on the reaction of ammonia with lithium chloride and magnesium chloride as respectively the low and high temperature salt. The thermodynamic properties of these salts are required to determine temperature lift and coefficient of performance. This paper presents the behavior of the low temperature salt, lithium chloride, under typical working conditions with temperatures ranging from ambient to $150^{\circ} \mathrm{C}$ and ammonia pressures ranging from 0.3 to 30 bars. Measurements using an HPDSC, an autoclave and a custom-made ammonia pressure cell have been conducted to determine the pressure-temperature lines and their corresponding enthalpy and entropy values for lithium chloride ammonia complexes. The results show a direct transformation of lithium chloride mono-ammonia to lithium chloride tri-ammonia complex for ammonia pressures up to 4 bars and temperatures up to $90^{\circ} \mathrm{C}$. At higher temperatures and pressures a stable, intermediate ammonia complex, lithium chloride di-ammonia complex, is formed. Under these conditions also a liquid phase has been observed. The latter can greatly affect the heat pump performance, both positive (no lattice degradation) as negative (escape from matrix, form impenetrable film).
\end{abstract}

Keywords: adsorption, ammonia, thermodynamic analysis, lithium chloride

\section{INTRODUCTION}

Lithium chloride is used as one of two sorbents in a heat pump type II cycle to upgrade industrial waste heat to above pinch temperatures[1;2]. This cycle uses the following reactions:
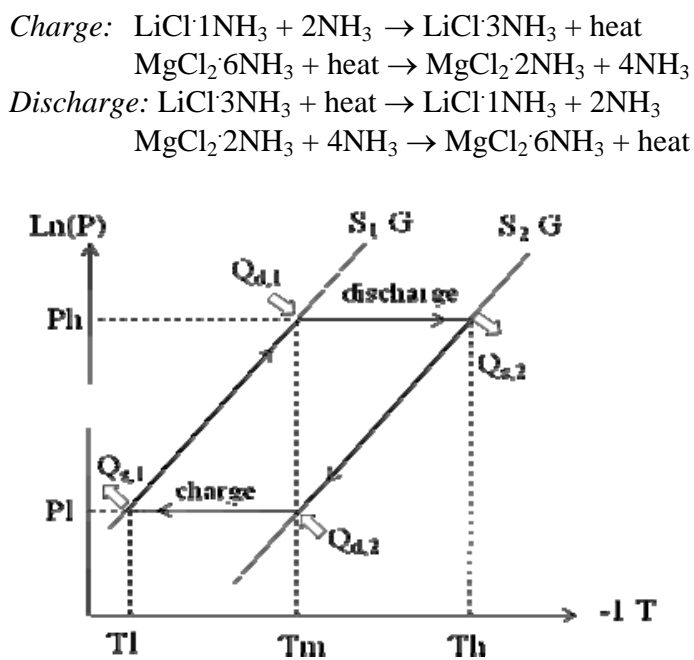

Figure 1. Thermodynamic cycle of a heat transformer $S_{1}=\mathrm{LiCl}(1-3) \mathrm{NH}_{3}$ and $S_{2}=\mathrm{MgCl}_{2}(2-6) \mathrm{NH}_{3}$.
This ammonia-salt pair has been carefully selected based on various criteria such as pressurerange, minimum operating temperature and required temperature lift. A more detailed description of this selection procedure can be found in Haije et al. $[1 ; 2]$.

For proper operation of the type II heat pump, including sufficient temperature lift, accurate information regarding the thermodynamic properties of both salts is required [3-5] This includes values of the sorption enthalpy, the pressure-temperature relations, including hysteresis, and additional properties that affect the thermal performance, e.g. phase change.

This paper focuses on determining the thermodynamic properties of lithium chloride using an HPDSC, an ammonia pressure cell and an autoclave. These thermodynamic properties include sorption enthalpy values and other thermal effects, for which the HPDSC results were used, and the pressure/temperature relation, which were based on results from the HPDSC ( 2 to 8 bar), ammonia pressure cell (for low ammonia pressures, $<2$ bar) and an autoclave (for high ammonia pressures, up to 40 bar). 
From literature it is known that for the temperature range from ambient up to $150^{\circ} \mathrm{C}$, lithium chloride can form various ammonia complexes varying from $\mathrm{LiCl} \cdot 1 \mathrm{NH}_{3}$ up to $\mathrm{LiCl} \cdot 5 \mathrm{NH}_{3}$. Bevers [2] has recently determined the enthalpy values for synthesis/decomposition of lithium chloride ammonia complexes up to $\mathrm{LiCl} \cdot 4 \mathrm{NH}_{3}$ using HPDSC and found three stable ammonia complexes below 4 bar pressure that, based on enthalpy value, were $\mathrm{LiCl} 1 \mathrm{NH}_{3}$, $\mathrm{LiCl} 3 \mathrm{NH}_{3}$ and $\mathrm{LiCl} 4 \mathrm{NH}_{3}$. For higher pressures a fourth stable ammonia complex is formed, likely the di-ammonia complex. This observation is in line with those of Bonnefoi [6] albeit Collins and Cameron [7] did not succeed in obtaining a stable diammonia complex. Kumao [8] focused on higher ammonia complexes of lithium chloride and reported the thermodynamic properties of a fifth ammonia complex: $\mathrm{LiCl}^{-5 \mathrm{NH}_{3}}$. The pressuretemperature range applied in the measurements described in this paper cover the range from $\mathrm{LiCl} 1 \mathrm{NH}_{3}$ to $\mathrm{LiCl} \cdot 5 \mathrm{NH}_{3}$.

\section{METHOD}

\section{HPDSC Analysis}

Lithium chloride (Merck, 99.0\%) was used as starting material. Due to the hygroscopic behavior of lithium chloride, the sample was weighed in a glovebox that was continuously flushed with dry air. After weighing, the sample was introduced in the HPDSC cell and the cell was flushed with nitrogen. At flushing, the atmosphere is changed to ammonia (purity $>99.98 \%$ ).

A Mettler-Toledo DSC27HP was used for the measurements in combination with a Brooks mass flow controller to assure a steady flow of ammonia at a rate of $50 \mathrm{ml}$ per minute, and a Brooks pressure controller to assure a steady ammonia pressure over the sample. The ammonia pressure was varied between 2 and 8 bar with a typical scan rate of $0.5^{\circ} \mathrm{C}$ per minute. A higher scan rate $\left(5^{\circ} \mathrm{C}\right.$ per minute) was applied for the repeated measurements.

\section{Ammonia pressure cell}

The ammonia pressure cell consists of a chamber wherein a salt sample can be placed and which can be evacuated and/or filled with ammonia. A temperature sensor is placed in the chamber as well as on the bottom of the chamber to measure temperature whilst a Eurotherm controller was used to keep the temperature at the required set point. A PTX1400 sensor (range: $0-6$ bar) was used to measure the pressure. Both temperature and pressure were monitored using a HP Agilent data logger.

At the start of the measurement a sample of lithium chloride was weighed and subsequently placed in the pressure cell. Subsequently the cell was evacuated for at least 10 minutes before the cell was filled with ammonia at desired pressure (just above equilibrium pressure) for at least 30 minutes. Subsequently the cell is shortly evacuated and filled again with ammonia. This procedure is repeated three times to convert most of lithium chloride into lithium chloride tris-ammonia complex. After this sample preparation procedure, the temperature of the cell is set in intervals of $10^{\circ} \mathrm{C}$ and the resulting equilibrium pressure is determined after 30 minutes.

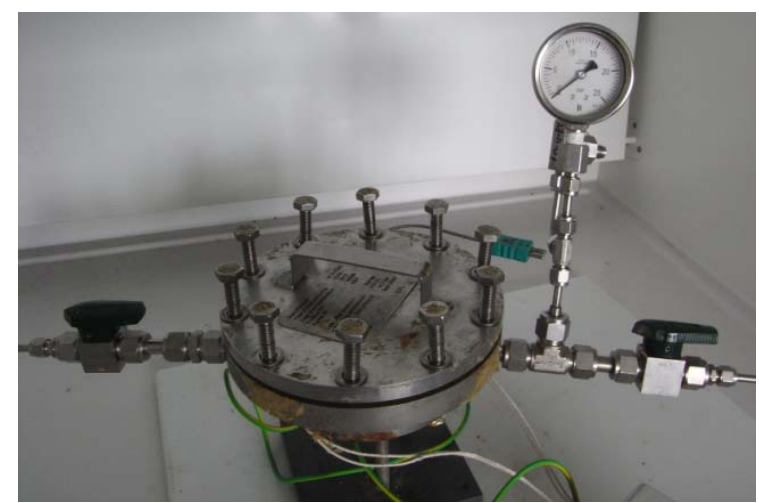

Figure 2. The ammonia pressure cell.

\section{Autoclave}

The measurements in the autoclave are similar to the ammonia pressure cell. The high-temperature resistant pressure sensor (PX1004) with a range of 0 to $100 \mathrm{bar}$ and a type $\mathrm{K}$ thermocouple placed inside the autoclave were used to monitor the pressure and temperature. The autoclave was placed in an oven that was set to run several thermal cycles of slowly heating up and cooling down. Due to the higher pressure (changes) and the resulting significant (varying) amounts of ammonia in the void volume, the autoclave was filled with inert material to avoid void space.

A practical problem with the preparation of the sample in the autoclave was the lack of a high pressure/high temperature resistant valve to close off the autoclave after charging the lithium chloride with ammonia. Instead the ammonia supply was detached, and replaced by a seal whereby, for a short period, ammonia could flow out of the autoclave. During this switch, a small but unknown amount of ammonia was released. Because the pressure in the autoclave exceeded ambient pressure no (significant amount of) air entered the autoclave. From the measured temperature - pressure relations, especially at relatively low pressures, it could be deducted which ammonia complex(es) were formed. 


\section{RESULTS}

\section{HPDSC results}

Figure 3 shows the results of repeated HPDSC measurements on lithium chloride at 3 bar with temperature varying between 60 and $100^{\circ} \mathrm{C}$. The reaction under these conditions is:

$$
\mathrm{LiCl} \cdot 1 \mathrm{NH}_{3}+2 \mathrm{NH}_{3} \leftrightarrow \mathrm{LiCl} \cdot 3 \mathrm{NH}_{3}+\text { heat }
$$

The HPDSC diagram shows the amount of heat required to keep the temperature equal to a reference sample as a function of temperature, which is increased at a constant rate in time. Therefore, the surface area is proportional to the total amount of heat adsorbed or desorbed by the lithium chloride. The first cycle shows the smallest peak and heat of reaction [9], with subsequently wider peaks with larger surface area until after approximately 25 cycles a steady state is achieved. This implies that the amount of heat of adsorption in the first cycle(s) is less than in the following ones. Apparently the lithium chloride matrix is not fully reacting in the first cycles and only after 25 cycles reaches a sufficient stability after which the amount of ammonia adsorbed and desorbed remains similar.

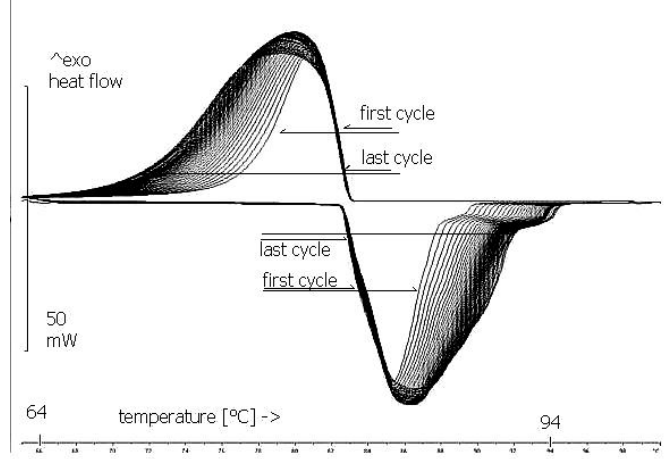

Figure 3. Repeated HPDSC measurements (3 bar, 60 to $100^{\circ} \mathrm{C}$ ) on lithium chloride, showing synthesis and decomposition of $\mathrm{LiCl} 3 \mathrm{NH}_{3}$.

Figure 4 and Figure 5 show the HPDSC diagrams for lithium chloride at respectively 3 and 5.5 bar. From the figures it can be observed that the left peak, which belongs to the synthesis of $\mathrm{LiCl} 3 \mathrm{NH}_{3}$, splits into two peaks at a higher pressure of 5.5 bar (see Figure 5). This indicates the formation of another, intermediate lithium chloride (di)ammonia complex.

The corresponding enthalpy values (per mole ammonia), derived from Clausius-Clapeyron plots, can be found in Table 1. In this table also the values found by Bevers [2] are given. The values are in good correspondence. Only the enthalpy (and entropy) value for the decomposition of $\mathrm{LiCl} 1 \mathrm{NH}_{3}$ de- viates significantly. A possible explanation could be that the hysteresis (i.e. the difference between adsorption and desorption enthalpy) is affected by the history (\# of cycles, the cycle time and/or temperature interval) of the lithium chloride matrix and differs here from Bevers' experiments. The amount of hysteresis found here has, however, only a minor effect on the performance of the type II heat pump application.

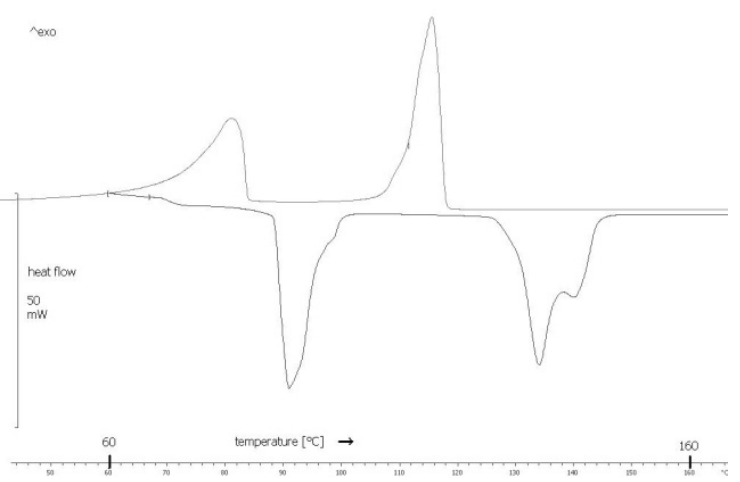

Figure 4. HPDSC diagram for synthesis and decomposition of $\mathrm{LiCl}^{3} \mathrm{NH}_{3}$ at 3 bar.

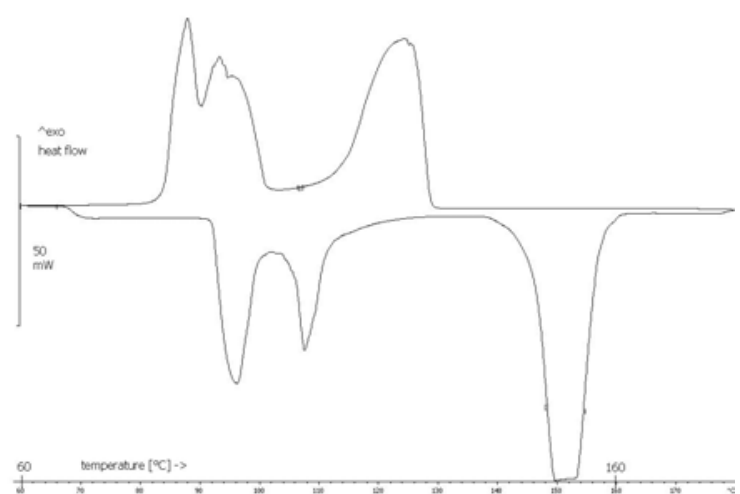

Figure 5. HPDSC diagram for synthesis and decomposition of $\mathrm{LiCl}_{3} \mathrm{NH}_{3}$ at 5.5 bar.

Table 1. Overview of measured data based on Clausius-Clapeyron and data from Bevers [2]

\begin{tabular}{llcccc}
\hline & & \multicolumn{2}{c}{$\Delta \mathrm{H}$} & \multicolumn{2}{c}{$\Delta \mathrm{S}$} \\
reaction & process & $\mathrm{J} / \mathrm{mol}$ & $\mathrm{J} / \mathrm{mol}$ & $\begin{array}{c}\text { Bevers } \\
\mathrm{J} / \mathrm{mol} \mathrm{K}\end{array}$ & $\mathrm{J} / \mathrm{mol} \mathrm{K}$ \\
\hline $\mathrm{LiCl}(3-4) \mathrm{NH}_{3}$ & Syn & 30431 & 30859 & 109.44 & 110.80 \\
& Dec & 36792 & 37461 & 126.60 & 128.90 \\
$\mathrm{LiCl}(1-3) \mathrm{NH}_{3}$ & Syn & 43681 & 45822 & 132.62 & 138.36 \\
& Dec & 49098 & 55267 & 146.58 & 163.90 \\
$\mathrm{LiCl}(0-1) \mathrm{NH}_{3}$ & Syn & 40470 & 41298 & 114.76 & 117.05 \\
& Dec & 60494 & 49338 & 159.43 & 133.46 \\
$\mathrm{LiCl}(1-2) \mathrm{NH}_{3}$ & Syn & & 22415 & & 74 \\
& Dec & & 18935 & & 64 \\
$\mathrm{LiCl}(3-2) \mathrm{NH}_{3}$ & Syn & & 75629 & & 222 \\
& Dec & & 62534 & & 184 \\
\hline
\end{tabular}

In addition to the synthesis of the various ammonia complexes, another peak was found in the HPDSC diagram for ammonia pressures of 5 bar and higher at a temperature of approximately $90^{\circ} \mathrm{C}$. Al- 
though it was difficult to find the peak for each pressure measurement above 5 bar, due to sorption peak, the position of this peak seemed pressureindependent. This is typical behavior for a phase change (i.e. solid to liquid phase). To confirm melting of the lithium chloride ammonia complex, various tests were conducted. The most convincing test was done using a glass vial in which lithium chloride was placed together with sufficient ammonia to form $\mathrm{LiCl} 3 \mathrm{NH}_{3}$ and subsequently sealed and heated up over $90^{\circ} \mathrm{C}$. The results are shown in Figure 6 and 7 . A clear liquid is observed when the vial is heated above $90^{\circ} \mathrm{C}$. Since the vial was sealed, the pressure is unknown.

Figure 8 shows the resulting pressuretemperature relation for lithium chloride ammonia complexes, including the phase change at higher temperatures. The lines show the trend lines based on the enthalpy and entropy values shown in Table 1. A more detailed figure with pressure - temperature relations for lithium chloride ammonia complexes from all measurements, HPDSC, pressure cell and autoclave, plus some additional literature data, can be found at the end of this paper (see Figure 11).
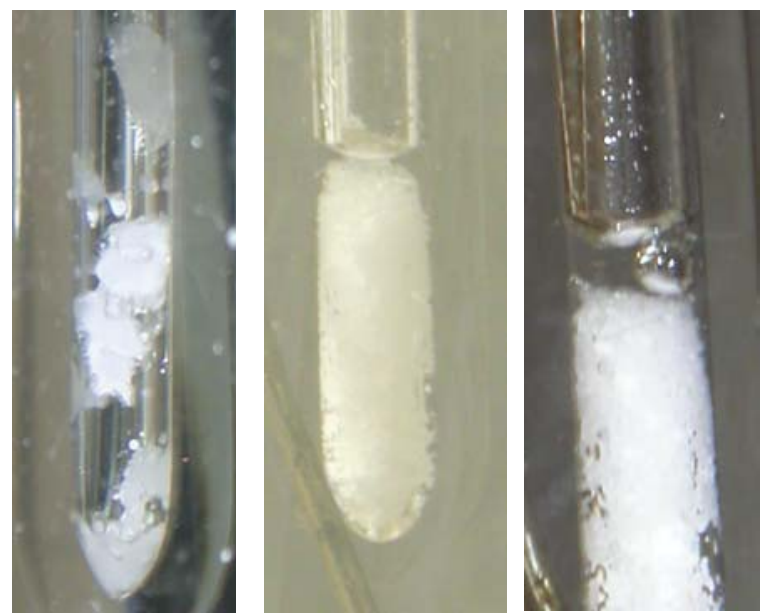

Figure 6. Clear liquid in sealed vial filled with lithium chloride ammonia complex at temperatures exceeding $90^{\circ} \mathrm{C}$.

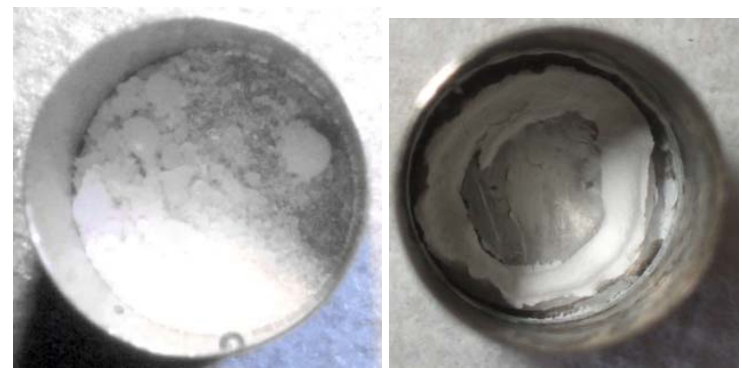

Figure 7.Left: lithium chloride in sample holder after low pressure run, Right: Lithium chloride after 6 bar pressure run.

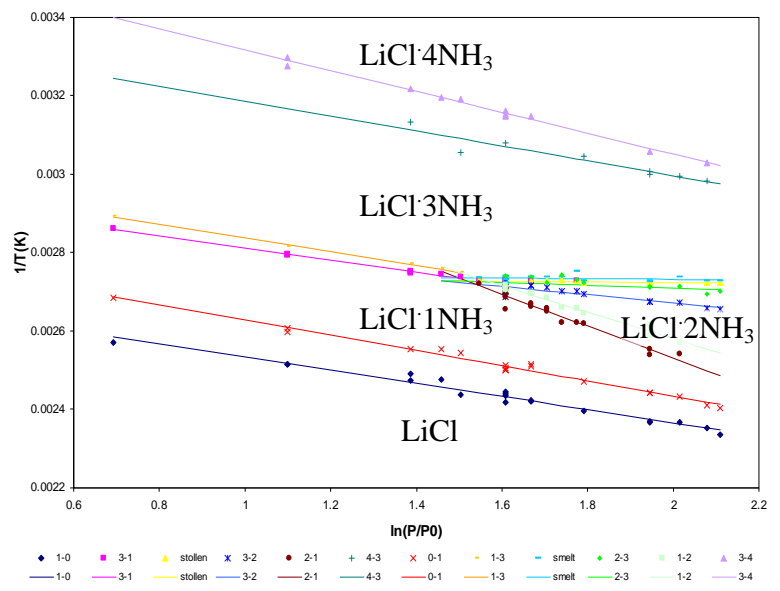

Figure 8. Pressure-temperature relations for lithium chloride ammonia complexes measured on HPDSC.

\section{Ammonia pressure cell}

Figure 9 shows the results of the temperature and pressure measurements in the ammonia pressure cell. The figure shows some scattering although the (linear) trend is clear. This trend shows the LiCl(13) $\mathrm{NH}_{3}$ synthesis/decomposition data.

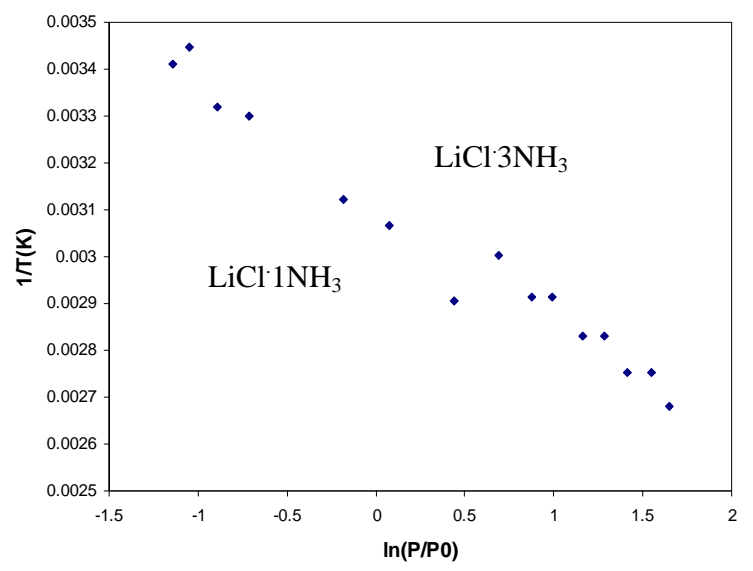

Figure 9. Measured pressure-temperature relation for synthesis of $\mathrm{LiCl} 3 \mathrm{NH}_{3}$ from $\mathrm{LiCl} 1 \mathrm{NH}_{3}$ using the ammonia pressure cell.

\section{Autoclave}

Figure 10 shows the results of the three autoclave measurements. Each color shows a separate measurement with black being the lithium chloride sample at the highest ammonia-complex to blue with the lowest. The red line, $\mathrm{LiCl}(2-3) \mathrm{NH}_{3}$ shows the variation in repeated temperature cycles. Furthermore, the increased ammonia uptake due to repeated synthesis/decomposition of the lithium chloride ammonia complex can also be observed in this measurement: after initially following the (red) equilibrium line for $\mathrm{LiCl}(3-4) \mathrm{NH}_{3}$, the equilibrium line for $\mathrm{LiCl}(2-3) \mathrm{NH}_{3}$ is followed in the second and third temperature cycle. 


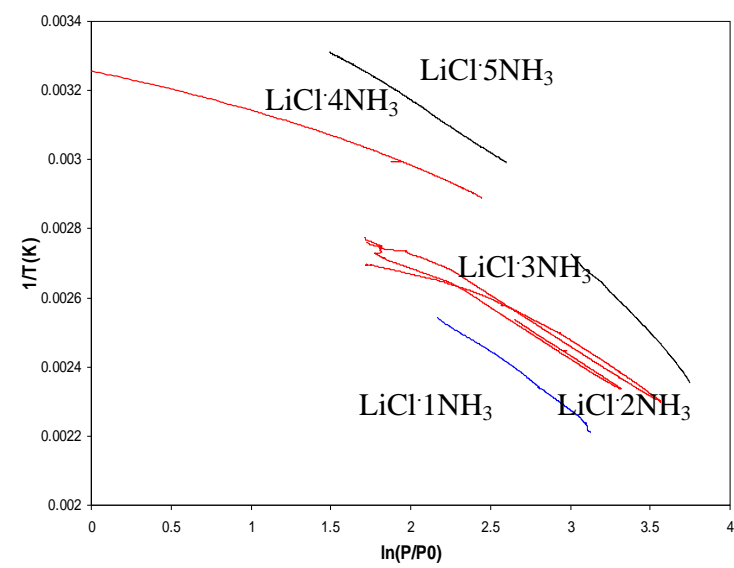

Figure 10. Pressure-temperature relations of lithium chloride ammonia complexes measured with the autoclave.

\section{DISCUSSION AND CONCLUSIONS}

The combined results of the measurements are shown in Figure 11 and are in good correlation with results found earlier by Bevers [2] and Bonnefoi [6] although the pressure values for the higher ammonia complexes are somewhat lower than measured by Kumao [8]. This includes the formation of a stable lithium chloride, $\mathrm{LiCl} 2 \mathrm{NH}_{3}$. The range for which these lithium chloride ammonia complexes have been measured, has been extended to pressures up to 40 bar. It was also shown a liquid phase exists. The latter can greatly affect heat pump performance, both positive and negative. First of all the matrix in which the sorbent is placed must be able to hold the liquid, otherwise it will escape its matrix and lose its functionality. This puts restraints on the possible reactor concepts that can be applied. Also the liquid phase can result in compacting of the sorbent or form an impenetrable film. These effects would seriously hamper the performance of the heat pump. The advantage of a liquid phase, however, is that the lattice is newly created in each cycle. This avoids degradation of the lattice which could extend the lifetime of the sorbent considerably. Also the liquid phase might yield a better contact with its matrix, improving heat transfer properties and thus lowering cycle times.

These challenges are addressed in our continuing research to optimize the chemical heat pump reactor design and its materials.

\section{REFERENCES}

1. W.G. Haije, J.B.J. Veldhuis, S.F. Smeding, R.J.H. Grisel, Solid/vapour sorption heat transformer: Design and performance, Applied Thermal Engineering 27 (2007) 1371-1376.
2. E.R.T. Bevers, P.J. van Ekeren, W.G. Haije, H.A.J. Oonk, Thermodynamic Properties of Lithium Chloride Ammonia complexes for Application in a High-Lift High Temperature Chemical Heat Pump, J. Therm. Anal. Calorim. 86 (2006) 825-832.

3. Y.I. Aristov, Novel materials for adsorptive heat pumping and storage: Screening and nanotailoring of sorption properties, J. Chem. Eng. Jpn. 40 (2007) 1242-1251, presented at IMPRES 2007.

4. Ph. Touzain. Thermodynamic values of ammonia-salt reactions for chemical sorption heat pumps. in: C. Schweigler, S. Summerer, H.M. Hellmann, and F. Ziegler. (Eds.)Proceedings of the International Sorption Heat Pump Conference, Munich, Germany, March 24-26, 1999 , 225-238. 1999. Garching, ZAE Bayern. ISHPC - International Sorption Heat Pump Conference.

5. B. Spinner, Ammonia-based thermochemical transformers, Heat Recovery Systems and CHP 13 (1993) 301-307.

6. J. Bonnefoi, Combinaisons des sels haloides du lithium avec l'ammoniac et les amines, Annales de Chimie et de Physique 23 (1901) 317-378.

7. S.C. Collins, F.K. Cameron, Lithium chloride ammonia complexes, The Journal of Physical Chemistry 32 (1928) 1705-1716.

8. S. Kumao, T. Toriumi, The solubilities of lithium chloride in liquid ammonia and the decomposition pressures of $\mathrm{LiCl}_{5} 5 \mathrm{NH}_{3}$ and LiCl.4NH 3 , Bull. Chem. Research Inst. NonAqueous Solns. , Tohoku Univ. 1 (1951) 125131.

9. J.S. Hummelshoj, R.Z. Sorensen, M.Y. Kustova, T. Johannessen, J.K. Norskov, C.H. Christensen, Generation of Nanopores during Desorption of $\mathrm{NH}_{3}$ from $\mathrm{Mg}\left(\mathrm{NH}_{3}\right)_{6} \mathrm{Cl}_{2}$, J. Am. Chem. Soc. 128 (2006) 16-17.

\section{ACKNOWLEDGEMENTS}

This work has been funded by AgentschapNL (Dutch agency for sustainable development and innovation) within the EOS-LT program, contract number

EOSLT07022. 


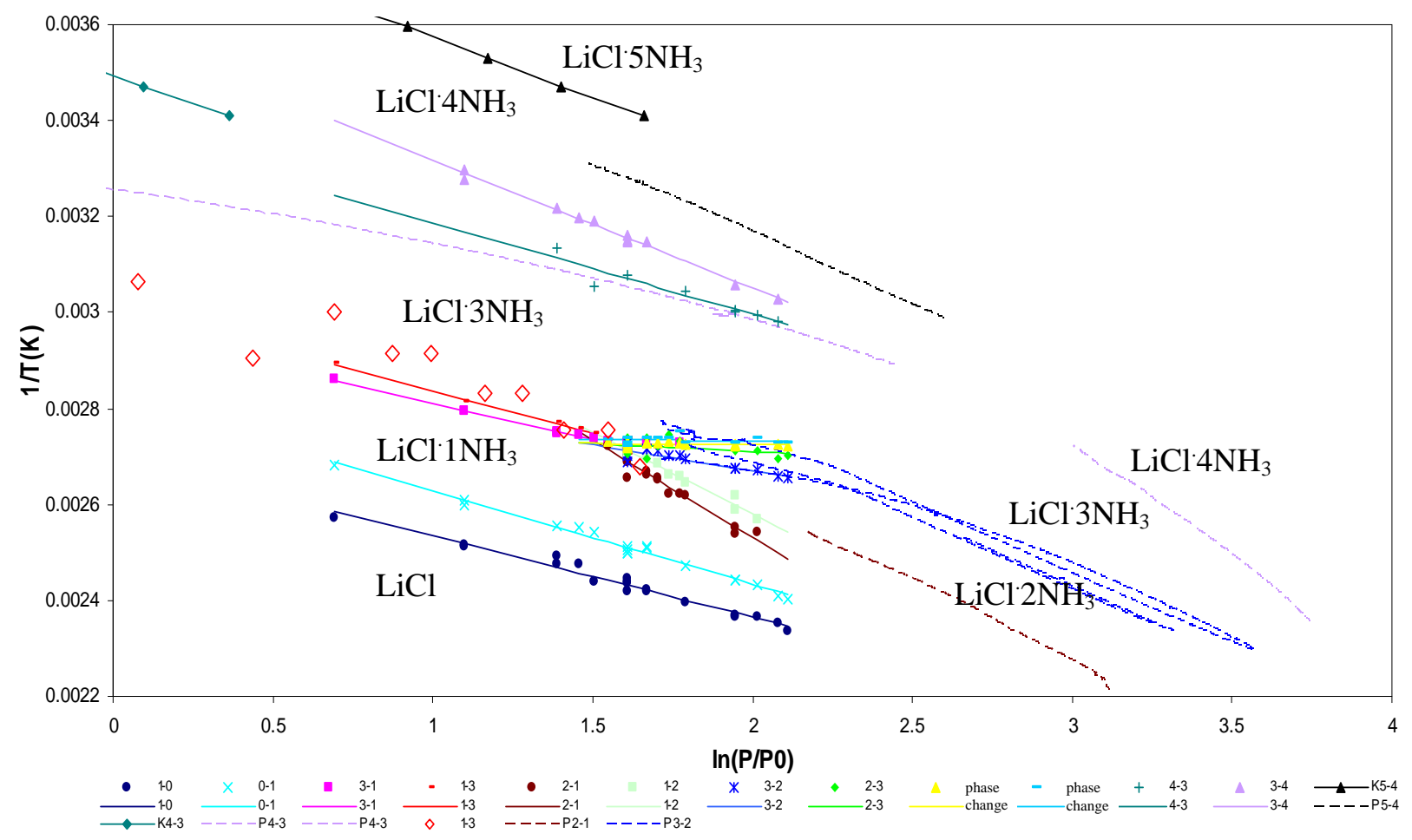

Figure 11. Overview of the combined pressure-temperature relations for lithium chloride ammonia complexes from the measurements in the ammonia pressure cell (low pressure, marked with open red square), the HPDSC (medium pressure) and the autoclave (high pressure, dotted lines, marked with P), together with literature data from Kumao, marked with $K$. 